\title{
Associations between dietary patterns, physical activity (leisure-time and occupational) and television viewing in middle-aged French adults
}

\author{
Hélène Charreire $^{1}$, Emmanuelle Kesse-Guyot ${ }^{1}$, Sandrine Bertrais ${ }^{1}$, Chantal Simon ${ }^{2}$, Basile Chaix ${ }^{3}$, \\ Christiane Weber $^{4}$, Mathilde Touvier ${ }^{1}$, Pilar Galan ${ }^{1}$, Serge Hercberg ${ }^{1,5}$ and Jean-Michel Oppert ${ }^{1,6 *}$ \\ ${ }^{1}$ INSERM U557, INRA U1125, CNAM, EA 3200, CRNH IdF, University Paris 13, 93017 Bobigny, France \\ ${ }^{2}$ Lyon University, INSERM U870, INRA U1235, CRNH Rhône-Alpes, Hospices Civils de Lyon, 69310 Pierre Bénite, France \\ ${ }^{3}$ INSERM U707, University Pierre et Marie Curie-Paris 6, 75012 Paris, France \\ ${ }^{4}$ ERL7230 CNRS Image, Ville, Environnement, Strasbourg University, 67000 Strasbourg, France \\ ${ }^{5}$ Department of Public Health, Avicenne Hospital (AP-HP), 93017 Bobigny, France \\ ${ }^{6}$ Department of Nutrition, Pitie-Salpetriere Hospital (AP-HP), 83, Boulevard de l'Hôpital, CNRH IdF, University Pierre et \\ Marie Curie-Paris 6, 75013 Paris, France \\ (Received 4 May 2010 - Revised 7 September 2010 - Accepted 28 September 2010 - First published online 21 January 2011)
}

\begin{abstract}
Diet and physical activity are considered to be major components of a healthy lifestyle. However, few studies have examined in detail the relationships between specific types of physical activity, sedentary behaviour and diet in adults. The objective of the present study was to assess differential relationships between dietary patterns, leisure-time and occupational physical activities and time spent watching television (TV), as an indicator of sedentary behaviour, in middle-aged French subjects. We performed a cross-sectional analysis using data from 1359 participants in the SUpplémentation en VItamines et Minéraux AntioXydants study, who completed a detailed physical activity questionnaire and at least six $24 \mathrm{~h}$ dietary records. Sex-specific dietary patterns were derived using factor analysis; their relationships with leisure-time and occupational physical activities and TV viewing were assessed using ANCOVA, after adjustment for age, educational level and smoking status. Three dietary patterns were identified in each sex. After adjustment for potential confounders, leisure-time physical activity was positively associated with a 'healthy' food pattern in both men $(P$ for trend $<0 \cdot 01)$ and women $(P$ for trend $<0 \cdot 03)$ and negatively associated with an 'alcohol/meat' pattern in men ( $P$ for trend $<0 \cdot 01)$. TV viewing was positively associated with a 'convenience' pattern in men and with a 'alcohol-appetiser' pattern in women. In conclusion, identification of relationships between dietary patterns, physical activity and sedentary behaviour can enable identification of different types of lifestyle and should help to target at-risk groups in nutrition prevention programmes.
\end{abstract}

Key words: Leisure-time physical activity: Occupational physical activity: Television viewing: Dietary patterns: Adults

As emphasised by the present global strategy of the $\mathrm{WHO}^{(1)}$, both a healthy diet and adequate physical activity are major factors in the prevention of chronic diseases and the promotion of good health throughout the entire lifespan. This is also reflected at a national level in many countries, with recommendations to engage in regular physical activity and reduce sedentary activities to promote health' in the dietary guidelines ${ }^{(2)}$.

Common types of physical activities consist of leisuretime (including sports), occupational, transport and at-home or domestic physical activity ${ }^{(3)}$. Studies in adult populations have shown that the specific domain of leisure-time physical activity, in contrast to occupational physical activity, is associated with healthier food intake ${ }^{(4,5)}$. In an attempt to overcome the limitations of traditional methods focusing on single nutrients or foods, analyses of overall dietary patterns have been proposed. By considering how foods are consumed in combination, dietary pattern analyses may provide a more comprehensive approach to food consumption and its relationship with other health behaviours or outcomes ${ }^{(6-9)}$. In a previous study, we reported, in a middle-aged French population, a negative relationship between a dietary pattern characterised by 'alcohol and meat' consumption and physical activity ${ }^{(10)}$. However, only an overall physical index across all contexts was used, and little is known about the association of

Abbreviations: MET, metabolic equivalent task; SU.VI.MAX, SUpplémentation en VItamines et Minéraux AntioXydants; TV, television. 
dietary patterns with specific types of habitual physical activity in adults.

Another important component of a healthy lifestyle lies in limiting sedentary behaviour. Sedentary time is the duration of an occupation that expends very little energy above the RMR, e.g. sitting or watching a screen ${ }^{(11-13)}$. It is generally agreed that sedentary behaviour and low physical activity levels are complementary aspects of human movement behaviour ${ }^{(13)}$ and are independent risk factors for major chronic diseases such as obesity and type 2 diabetes, cardiometabolic risk and mortality ${ }^{(11-14)}$. Sedentary behaviour was found to be associated with consumption of unhealthy foods in youth ${ }^{(15-18)}$. In adults, evidence of such an association is rare ${ }^{(19,20)}$.

A more thorough understanding of the relationship between dietary habits, physical activity and sedentary behaviour is needed to better define a healthy lifestyle and target at-risk groups in nutrition prevention programmes. Therefore, the aim of the present study was to investigate the differential relationship of dietary patterns with various types of physical activity and with time spent watching television (TV), used as an indicator of sedentary behaviour, in middle-aged French subjects.

\section{Methods}

\section{Subjects and study design}

Subjects were participants in the SUpplémentation en VItamines et Minéraux AntioXydants (SU.VI.MAX) study. This study is a randomised, double-blind, placebocontrolled primary prevention trial designed to evaluate the impact of daily antioxidant supplementation at nutritional doses on the incidence of CVD and cancer ${ }^{(21,22)}$. A total of 5028 men aged 45-60 years and 7713 women aged 35-60 years from throughout France were included between October 1994 and June 1995, with a planned follow-up of 8 years. The present study was conducted according to the guidelines laid down in the Declaration of Helsinki and all procedures involving human subjects were approved by the Ethical Committee for Studies with Human Subjects at the Paris-Cochin Hospital (CCPPRB no. 706) and the Commission Nationale Informatique et Liberté (CNIL no. 334641). Written informed consent was obtained from all subjects.

For the present study, only subjects with available data on leisure-time and occupational physical activities in 1998 and who had also completed at least six 24 h dietary records during the same period were included. In order to obtain a similar age range in both sexes, the sample was further restricted to subjects aged 45 years or older in 1998. We also excluded subjects who had had a major health event (CVD and cancer) and/or had been confined to bed for more than 1 month during the period covered by the physical activity questionnaire. Analyses in the present report were based on data from 701 men and 658 women.

\section{Dietary assessment}

Subjects were asked to provide a $24 \mathrm{~h}$ dietary record every 2 months for a total of six records per year. Dietary data were collected using the Minitel Telematic Network ${ }^{(21)}$. This specific tool was a small terminal widely used in France during the 1990s, at the beginning of the SU.VI.MAX study $^{(21)}$. At enrolment, participants received this tool and a validated instruction manual of photographs to assist in coding food portions ${ }^{(23)}$. Dietary nutrient intakes, based on the average daily intake for each subject, were estimated using a French food composition table ${ }^{(24)}$.

\section{Dietary patterns}

Dietary patterns were defined by factor analysis using a principal component analysis method that has been previously reported $^{(10)}$. Among 900 recorded food items, thirty-seven food groups were defined according to the type of food or nutrient content (see the Supplementary material of KesseGuyot et al.) ${ }^{(10)}$ and each food group was energy-adjusted using the residual method ${ }^{(25)}$. PROC FACTOR in SAS version 9.1 (SAS Institute, Inc., Cary, NC, USA) with the SAS 'Varimax' option was applied by sex to derive dietary patterns on the basis of food groups. The number of retained patterns was determined according to several criteria: Eigenvalue $>1$, screen test (the plot of the total variance related to each factor) and interpretability. Dietary patterns were labelled on the basis of food groups that were found to be strongly correlated with each extracted pattern (factor loading coefficient $>0.30$ ). In a final step for each participant, a factor score was calculated for each pattern by summing up the energy-adjusted food group intakes, which were weighted by its scoring coefficient.

\section{Assessment of physical activity and sedentary behaviour}

Physical activity and sedentary behaviour were assessed using the French self-administered version of the modifiable activity questionnaire ${ }^{(26)}$. The modifiable activity questionnaire, developed by Kriska et al. ${ }^{(27)}$, assesses past 12-month physical activity during leisure time and work. Physical activity assessment using the Modifiable Activity Questionnaire has been validated against energy expenditure measurements, using the double-labelled technique; the test-retest properties of the questionnaire have been demonstrated ${ }^{(28)}$. The questionnaire has been described in detail elsewhere ${ }^{(26-28)}$. Briefly, for leisuretime physical activity, subjects were asked to report all leisure-time physical activities performed at least ten times for $10 \mathrm{~min} / \mathrm{session}$ over the past 12 months. Detailed information was collected concerning the type of leisure activity (walking, cycling, swimming, gardening, etc.) The frequency (average number of times/month) and duration (average number of minutes each time) of each activity were reported. Minutes per week for all leisure-time activities were summed up to obtain an 
indicator expressed in h/week. An energy expenditure indicator was also calculated by multiplying the number of $\mathrm{h} /$ week of each physical activity by its estimated metabolic cost ${ }^{(29)}$. This indicator was expressed in metabolic equivalent task (MET)-h/week of leisure-time activity.

Assessment of occupational physical activity was based on the number of hours during which an individual participated in physically demanding activities during an average work day for each job held over the past year. The number of hours in each of three categories of occupational physical activity (low, moderate and vigorous) was multiplied by an average group MET value (2, 4 and 7 MET, respectively) ${ }^{(26)}$ and then summed up, resulting in a final occupational activity estimate expressed in MET-h/week. Total physical activity over the past year was determined as the sum of leisure-time and occupational activity indicators (expressed in $\mathrm{h} /$ week and in MET-h/week of activity). The questionnaire also includes information about time spent daily watching TV that was measured using a question: 'in general, how many hours a day do you spend viewing TV?' (h/d). TV viewing time was categorised into four classes $(<1,1-2,2-3$ and $\geq 3 \mathrm{~h} / \mathrm{d})$.

\section{Covariates}

Socio-demographic data (sex, age and level of education) and smoking status were obtained through self-administered questionnaires at study entry and with specific questionnaires during the follow-up (smoking status). The level of education was coded into three categories according to the highest certification obtained (primary school, high school and university or equivalent). Three classes were used for smoking status (never smokers, present smokers and former smokers).

\section{Statistical analyses}

All analyses were performed separately for men and women because we expected that women and men would have different physical activities and dietary patterns. Means were compared using Student's $t$ tests, while $\chi^{2}$ tests were used to compare frequencies and Wilcoxon-MannWhitney tests for scoring variables. Spearman's correlations were used to examine the associations between the different physical activity domains and TV viewing. In further analyses, scores for leisure-time, occupational and total physical activities were categorised into three equal groups by using tertile cut-offs. Comparisons of dietary patterns across tertiles of the leisure-time physical activity score, tertiles of the occupational physical activity score, tertiles of total physical activity and TV viewing were assessed by ANCOVA (using the general linear model), controlling for age, education level and smoking status.

Additional adjustments for physical activity domains were applied: the relationship between leisure-time physical activity and dietary patterns was adjusted for occupational physical activity and TV viewing; that between occupational physical activity and dietary patterns was adjusted for leisure-time physical activity and TV viewing; that between TV viewing and dietary patterns was adjusted for both physical activity domains. Statistical analyses were performed using SAS package version 9.1. The level of significance for acceptance was $P<0 \cdot 05$.

\section{Results}

\section{Characteristics of the study population}

Table 1 presents the characteristics of the study subjects. Compared with men, women were younger, better educated, smoked less, had lower total energy and alcohol intake and had lower levels of leisure-time, occupational and total physical activities. The mean total physical activity was higher in men than in women (23.3 and 19.5 h/week, 83.8 and 59.9 MET-h/week in men and women, respectively).

\section{Dietary patterns}

Three major dietary patterns were identified in both sexes and accounted for $17 \cdot 6 \%$ of the total initial variance of food intakes in men and $16.3 \%$ in women. Table 2 describes factor loadings for these three patterns. The first pattern was labelled 'alcohol/meat' in men and 'alcohol/appetisers' in women. It was characterised by a high consumption of alcohol (wine and other alcoholic beverages) in both sexes. This pattern was also characterised by a high consumption of meat ('meat and poultry' group and 'processed meat' group) in men and by a high consumption of appetisers (salted crackers, chips and olives) in women. The second pattern, which was a 'healthy food' pattern, was identified in both sexes. It had positive coefficients for intake of vegetables, vegetable oil and fat-free or low-fat sauces, and a negative coefficient for butter intake. More specifically, in men, this pattern was also characterised by a high consumption of fruits, starch, fish and seafood, breakfast cereals and dairy products. In women, the 'healthy food' pattern was also characterised by a high consumption of reduced-fat products and cheese and a low consumption of sweetened products, bread and crisps. The third dietary pattern was labelled 'convenience food' in both sexes. It was characterised by positive coefficients for ready-to-eat products, desserts, candy, cookies and croissants, and negative coefficients for vegetables, vegetable oil, meat and poultry.

\section{Association between dietary patterns, physical activity and sedentary behaviour}

Relationships between dietary patterns, leisure-time, occupational and total physical activities and TV viewing are shown separately for men (Table 3 ) and women (Table 4). 
Table 1. General characteristics of the study subjects

(Mean values and standard deviations or percentages)

\begin{tabular}{|c|c|c|c|c|c|}
\hline & \multicolumn{2}{|c|}{ Men $(n 701)$} & \multicolumn{2}{|c|}{ Women ( $n$ 658) } & \multirow[b]{2}{*}{$P$} \\
\hline & Mean & SD & Mean & SD & \\
\hline Age (years) ${ }^{\star}$ & $54 \cdot 2$ & $4 \cdot 2$ & $51 \cdot 8$ & 4.6 & $<0.0001$ \\
\hline \multicolumn{6}{|l|}{ Education level (\%)† } \\
\hline Primary & \multicolumn{2}{|c|}{21.5} & \multicolumn{2}{|c|}{$14 \cdot 3$} & \\
\hline Secondary & \multicolumn{2}{|c|}{$35 \cdot 0$} & \multicolumn{2}{|c|}{$44 \cdot 8$} & \\
\hline University & \multicolumn{2}{|c|}{43.5} & \multicolumn{2}{|c|}{40.9} & $<0.0001$ \\
\hline \multicolumn{6}{|l|}{ Smoking status $(\%) \dagger$} \\
\hline Never smoker & \multirow{2}{*}{\multicolumn{2}{|c|}{$29 \cdot 7$}} & \multicolumn{2}{|c|}{$54 \cdot 3$} & \\
\hline Former smoker & \multirow{2}{*}{\multicolumn{2}{|c|}{$\begin{array}{l}57 \cdot 1 \\
13 \cdot 3\end{array}$}} & \multirow{2}{*}{\multicolumn{2}{|c|}{32.5}} & \\
\hline Present smoker & & & & & $<0.0001$ \\
\hline Energy intake $(\mathrm{kJ} / \mathrm{d})^{\star}$ & 10205 & 2223 & 7572 & 1842 & $<0.0001$ \\
\hline \multicolumn{6}{|c|}{ Percentage of total daily energy intake ${ }^{*}$} \\
\hline Carbohydrates & 39.5 & 7.6 & $40 \cdot 8$ & 6.6 & 0.0008 \\
\hline Protein & $16 \cdot 2$ & $2 \cdot 6$ & $16 \cdot 6$ & $2 \cdot 7$ & 0.0003 \\
\hline Fat & 35.7 & $5 \cdot 4$ & 37.8 & $5 \cdot 2$ & $<0.0001$ \\
\hline Alcohol & $8 \cdot 6$ & $6 \cdot 9$ & $4 \cdot 8$ & $5 \cdot 5$ & $<0.0001$ \\
\hline \multicolumn{6}{|l|}{ Physical activity (h/week) } \\
\hline Leisure-time physical activitył & 4.4 & $4 \cdot 8$ & 3.3 & 3.8 & $<0.0001$ \\
\hline Occupational physical activity & 18.9 & 13.2 & $16 \cdot 2$ & $12 \cdot 6$ & $<0.0001$ \\
\hline Total physical activity $\ddagger$ & $23 \cdot 3$ & $14 \cdot 1$ & 19.5 & 13.5 & $<0.0001$ \\
\hline \multicolumn{6}{|l|}{ Physical activity (MET-h/week) } \\
\hline Leisure-time physical activity & $21 \cdot 1$ & 23.4 & $15 \cdot 3$ & 18.2 & $<0.0001$ \\
\hline Occupational physical activitył & $62 \cdot 7$ & $70 \cdot 6$ & 44.6 & $48 . \overline{5}$ & $<0.0001$ \\
\hline Total physical activitył & $83 \cdot 8$ & $74 \cdot 3$ & 59.9 & 53.4 & $<0.0001$ \\
\hline \multicolumn{6}{|l|}{ TV watching $(\%) \dagger(\mathrm{h} / \mathrm{d})$} \\
\hline$<1$ & \multicolumn{2}{|c|}{$13 \cdot 5$} & \multicolumn{2}{|c|}{$16 \cdot 1$} & \\
\hline $1-2$ & \multicolumn{2}{|c|}{$32 \cdot 8$} & \multicolumn{2}{|c|}{$30 \cdot 2$} & \\
\hline $2-3$ & \multicolumn{2}{|c|}{$35 \cdot 7$} & \multicolumn{2}{|c|}{34.2} & \\
\hline$\geq 3$ & \multicolumn{2}{|c|}{$\begin{array}{l}30 \cdot 1 \\
18 \cdot 0\end{array}$} & \multicolumn{2}{|c|}{$\begin{array}{l}34 \cdot 2 \\
19 \cdot 5\end{array}$} & 0.40 \\
\hline
\end{tabular}

MET, metabolic equivalent task; TV, television.

* Comparison between men and women by Student's $t$ test.

$\dagger$ Comparison between men and women by the $\chi^{2}$ test.

$\ddagger$ Comparison between men and women by the Wilcoxon-Mann-Whitney test.

In contrast to the results for each physical activity domain, there was no significant association between dietary patterns and total physical activity in either sex. In men, the 'alcohol/ meat' pattern was negatively associated with leisure-time physical activity and was not associated with occupational physical activity or with TV viewing. In women, the 'alcohol/appetisers' pattern was positively associated with TV viewing. For the 'healthy food' pattern, significant positive associations were observed with leisure-time physical activity in men and women. In men, there was a trend (non-significant) towards an inverse association between the 'healthy food' pattern and occupational physical activity. In both sexes, there was no association between the healthy food' pattern and TV viewing. In men, the 'convenience food' pattern was positively associated with TV viewing. In women, there was a trend (non-significant) towards an inverse relationship between the 'convenience food' pattern and leisure-time physical activity, whereas that same dietary pattern tended to be positively related to occupational physical activity and no association was found with TV viewing. In addition, none of the correlations between a given physical activity domain and TV viewing was significant, either in men or in women (coefficients ranged from $r-0.04$ to $0 \cdot 04$ ).

\section{Discussion}

In a population of middle-aged French men and women, we identified three dietary patterns in both sexes. Although we observed some sex differences in consumption of specific foods such as appetisers for women and meat for men, two of these patterns were broadly similar in each sex ('healthy food' and 'convenience food' patterns). Leisure-time physical activity was consistently and positively associated with the 'healthy food' pattern in both sexes. Associations between physical activity at work and dietary patterns seemed less consistent in both sexes. TV viewing was found to be associated with less healthy dietary habits, as it was related to the 'alcohol/meat' pattern in men and the 'convenience food' pattern in women. The relationships between TV viewing and different physical activity domains (leisure, occupational and total) were non-significant, both in men and women.

Previous research investigating the relationship between diet and physical activity behaviour mainly focused on the effects of individual nutrients and/or specific foods or food groups $^{(5,30)}$. To better account for the complexity of an individual diet combining various nutrients or foods ${ }^{(31,32)}$, we used the dietary pattern approach ${ }^{(10)}$ to investigate its relationship with the types of physical activity and 
Table 2. Factor loadings for the three dietary patterns derived from factor analysis*

\begin{tabular}{|c|c|c|c|c|c|c|}
\hline & \multicolumn{3}{|c|}{ Men } & \multicolumn{3}{|c|}{ Women } \\
\hline & $\begin{array}{c}\text { Factor } 1 \\
\text { Alcohol/meat }\end{array}$ & $\begin{array}{l}\text { Factor } 2 \\
\text { Healthy food }\end{array}$ & $\begin{array}{c}\text { Factor } 3 \\
\text { Convenience food }\end{array}$ & $\begin{array}{c}\text { Factor } 1 \\
\text { Alcohol/appetisers }\end{array}$ & $\begin{array}{c}\text { Factor } 2 \\
\text { Healthy food }\end{array}$ & $\begin{array}{c}\text { Factor } 3 \\
\text { Convenience food }\end{array}$ \\
\hline Meat and poultry & 0.37 & & & & & -0.37 \\
\hline Processed meat & 0.33 & & & & & \\
\hline Candy and cookies & & & 0.41 & & & 0.46 \\
\hline $\begin{array}{l}\text { Eggs } \\
\text { Fruits }\end{array}$ & & 0.39 & & -0.55 & & \\
\hline Desserts & & & 0.48 & & & 0.58 \\
\hline $\begin{array}{l}\text { Alcoholic beverages } \\
\text { Beer and cider }\end{array}$ & 0.55 & דיב? & & 0.54 & & \\
\hline Wine & 0.64 & -0.31 & & 0.58 & & -0.36 \\
\hline $\begin{array}{l}\text { Coffee } \\
\text { Tea }\end{array}$ & & -0.32 & & & & \\
\hline Sweetened beverages & & & 0.31 & & & \\
\hline Fruit juice & & & 0.32 & & & \\
\hline Water & & & & & & \\
\hline Mineral water & & & & & & \\
\hline Rice and pasta & & 0.35 & & & & \\
\hline Potatoes & & & -0.32 & & & \\
\hline Butter & & -0.33 & & & -0.53 & \\
\hline Margarine & & & & & & \\
\hline $\begin{array}{l}\text { Vegetable oil } \\
\text { Sauces }\end{array}$ & & 0.51 & -0.36 & & 0.35 & -0.33 \\
\hline Fat-free or low-fat sauces & & 0.33 & & & 0.32 & \\
\hline Bread and crisps & -0.58 & & -0.37 & -0.36 & -0.45 & \\
\hline Breakfast cereals & & 0.36 & & & & \\
\hline Sweetened products & -0.53 & & & & -0.46 & \\
\hline $\begin{array}{l}\text { Vegetables } \\
\text { Dried vegetables }\end{array}$ & & 0.55 & & & 0.48 & -0.37 \\
\hline Soup & -0.38 & & & -0.34 & & \\
\hline Fish and seafood & & 0.35 & & & & \\
\hline Cheese & & & & & 0.36 & \\
\hline Milk & & & & & & \\
\hline Dairy products & & 0.31 & & -0.37 & & \\
\hline Ready-to-eat products & & & 0.52 & & & 0.35 \\
\hline Croissants & & & 0.39 & & & 0.42 \\
\hline Appetisers & & & & 0.46 & & \\
\hline Reduced-fat products & & & & & 0.33 & \\
\hline
\end{tabular}

${ }^{*}$ Absolute values $<0.30$ were not represented in the table for simplicity.

sedentary behaviour. A strength of the present study was the use of a detailed physical activity questionnaire that enabled us to analyse the differential association of leisure-time and occupational physical activities with various dietary profiles. In the subjects of the present study, independently of age, educational level, smoking status or occupational physical activity, a high level of leisuretime physical activity was found to be associated with a high consumption of healthy foods such as fruits (in men) and vegetables (in both sexes). In adults, comparable relationships between leisure-time physical activity and a healthy diet (characterised by intakes of specific macronutrients or food groups) have been reported in previous studies ${ }^{(4,33-36)}$. In adult subjects, in the Worcester Area Trial for Counseling in Hyperlipidemia study ${ }^{(34)}$, individuals active during leisure time consumed more fruits and vegetables and less fat from dairy products than inactive subjects ${ }^{(34)}$. Among adult participants in the Harvard Pilgrim Health Care, Gillman et al. ${ }^{(35)}$ found that increased physical activity was significantly associated with a higher consumption of healthy food and that 'non-exercisers or only occasional exercisers' had suboptimal dietary intakes. The present study extends these findings of a positive relationship between leisure-time physical activity and healthy dietary patterns to a middleaged French population.

In contrast, an inverse association was found between leisure-time physical activity and the alcohol (alcoholic beverages and wine) and meat (meat, processed meat and poultry) pattern in men. Fung et al. ${ }^{(37)}$ also previously reported that a dietary pattern characterised by higher intakes of red meat, high-fat dairy products, beer and liquor ('Western pattern') in men was associated with less leisure-time physical activity. However, in that study, only leisure-time physical activity was assessed.

In the present analyses, the associations between occupational physical activity and dietary patterns were less consistent than with leisure-time physical activity, as none reached statistical significance, despite borderline trends suggesting an association of occupational physical 
Table 3. Relationship of dietary patterns with physical activity and television (TV) viewing in men (Adjusted* mean values and significant association using ANCOVA)

\begin{tabular}{|c|c|c|c|c|c|c|}
\hline & \multicolumn{2}{|c|}{ Alcohol/meat } & \multicolumn{2}{|c|}{ Healthy food } & \multicolumn{2}{|c|}{ Convenience food } \\
\hline & Mean & $P$ trend & Mean & $P$ trend & Mean & $P$ trend \\
\hline \multicolumn{7}{|c|}{ Leisure-time physical activity (MET-h/week) } \\
\hline$<8.4$ & 0.10 & 0.01 & -0.09 & 0.01 & -0.05 & 0.19 \\
\hline $8 \cdot 4-22 \cdot 4$ & 0.05 & & -0.07 & & -0.01 & \\
\hline$>22.4$ & -0.14 & & 0.16 & & 0.07 & \\
\hline \multicolumn{7}{|c|}{ Occupational physical activity (MET-h/week) } \\
\hline$<23.8$ & 0.05 & 0.29 & 0.06 & 0.06 & 0.04 & 0.33 \\
\hline $23 \cdot 8-59 \cdot 5$ & -0.01 & & 0.05 & & 0.01 & \\
\hline$>59.5$ & -0.05 & & $-0 \cdot 12$ & & -0.06 & \\
\hline \multicolumn{7}{|c|}{ Total physical activity (MET-h/week) } \\
\hline$<42 \cdot 1$ & 0.05 & 0.15 & 0.01 & 0.41 & 0.04 & 0.24 \\
\hline $42 \cdot 1-86 \cdot 1$ & 0.03 & & 0.06 & & 0.03 & \\
\hline$>86.1$ & -0.09 & & -0.07 & & -0.07 & \\
\hline \multicolumn{7}{|c|}{ TV viewing $(\mathrm{h} / \mathrm{d})$} \\
\hline$<1$ & -0.21 & $0 \cdot 12$ & 0.10 & 0.38 & -0.26 & 0.04 \\
\hline $1-2$ & 0.04 & & -0.03 & & 0.04 & \\
\hline $2-3$ & 0.03 & & 0.01 & & 0.05 & \\
\hline$\geq 3$ & 0.02 & & -0.04 & & 0.02 & \\
\hline
\end{tabular}

MET, metabolic equivalent task.

* Adjustment analysis: controlling for age, educational level and smoking status and additional adjustment for other physical activity domains and TV viewing.

† Adjustment analysis: additional adjustment for both leisure-time and occupational physical activities.

activity with the 'healthy food' pattern in men (inverse association) and with the 'convenience food' pattern in women (positive association). In a recent study, Camoes $\&$ Lopes $^{(5)}$ also reported less association between dietary intake and occupational physical activity than with leisure-time physical activity, and only a significant positive association of occupational physical activity with energy intake was observed in men. This result may be explained, at least in part, by the difficulty in assessing the different aspects of occupational physical activity and reporting the number of hours of physical activities during an average workday. Occupational physical activity appears in itself to include a combination of various activities that might be differentially associated with health behaviours ${ }^{(38)}$.

One original aspect of the present study is that we analysed the association between time spent watching TV and dietary patterns accounting for both leisure-time and occupational physical activities. Overall, the results show that TV viewing was positively related to unhealthy dietary

Table 4. Relationship of dietary patterns with physical activity and television (TV) viewing in women

(Adjusted* mean values and significant association using ANCOVA)

\begin{tabular}{|c|c|c|c|c|c|c|}
\hline & \multicolumn{2}{|c|}{ Alcohol/appetisers } & \multicolumn{2}{|c|}{ Healthy food } & \multicolumn{2}{|c|}{ Convenience food } \\
\hline & Mean & $P$ trend & Mean & $P$ trend & Mean & $P$ trend \\
\hline \multicolumn{7}{|c|}{ Leisure-time physical activity (MET-h/week) } \\
\hline$<5.5$ & 0.06 & 0.29 & -0.11 & 0.03 & 0.13 & 0.07 \\
\hline $5 \cdot 5-16$ & -0.02 & & 0.01 & & -0.08 & \\
\hline$>16$ & -0.04 & & $0 \cdot 10$ & & -0.05 & \\
\hline \multicolumn{7}{|c|}{ Occupational physical activity (MET-h/week) } \\
\hline$<18 \cdot 3$ & -0.15 & 0.30 & 0.06 & $0 \cdot 17$ & -0.08 & 0.07 \\
\hline $18 \cdot 4-47 \cdot 6$ & 0.17 & & 0.02 & & -0.01 & \\
\hline$>47.6$ & -0.05 & & -0.08 & & 0.09 & \\
\hline \multicolumn{7}{|c|}{ Total physical activity (MET-h/week) } \\
\hline$<32.4$ & -0.08 & 0.28 & 0.03 & 0.43 & -0.09 & 0.09 \\
\hline $32 \cdot 4-62 \cdot 6$ & 0.07 & & 0.02 & & 0.02 & \\
\hline$>62 \cdot 6$ & 0.02 & & -0.05 & & 0.07 & \\
\hline \multicolumn{7}{|c|}{ TV viewingt $(\mathrm{h} / \mathrm{d})$} \\
\hline$<1$ & -0.12 & 0.03 & -0.04 & 0.68 & 0.04 & 0.30 \\
\hline $1-2$ & -0.05 & & 0.03 & & -0.09 & \\
\hline $2-3$ & 0.02 & & -0.05 & & -0.02 & \\
\hline$\geq 3$ & 0.14 & & 0.06 & & 0.14 & \\
\hline
\end{tabular}

MET, metabolic equivalent task.

${ }^{*}$ Adjustment analysis: controlling for age, educational level and smoking status and additional adjustment for other physical activity domains.

† Adjustment analysis: additional adjustment for both leisure-time and occupational physical activities. 
patterns characterised by the 'convenience food' pattern in men (a high consumption of sweetened beverages, readyto-eat products, croissants, desserts, candy and cookies) and the 'alcohol/appetisers' pattern in women, independently of physical activity. Similar associations between high levels of sedentary behaviour and high consumption of snack foods ${ }^{(39)}$, sugar-sweetened soda ${ }^{(20)}$ and fast foods $^{(40)}$ have been observed in previous studies. Altogether, these findings of an association between unhealthy dietary patterns and sedentary behaviour may help explain, at least in part, the relationship between sedentary behaviour and body-weight gain during adult$\operatorname{hood}^{(39)}$. In children, the data from a recent study suggested that the association between TV viewing and body fatness was likely to be due to an association with increased energy intake since the effect of TV viewing on fatness was not mediated by physical activity ${ }^{(41)}$. In adults, the absence of correlations between TV viewing and domains of physical activity, in agreement with previous investigations ${ }^{(13,42-45)}$, means that physical activity and sedentary behaviour represent distinct domains requiring specific assessments and interventions.

Interestingly, we observed no significant relationship between total physical activity and dietary patterns. These results are in line with previous recent reports in which few relationships were evidenced when using only an overall physical activity variable ${ }^{(5,10)}$. Except for energy intake in men, Camoes \& Lopes reported no difference in the relationship between total physical activity and dietary intake in active $v$. sedentary subjects. Likewise, in an adult population in the European Union, relationships were found between health indicators (self-rated health and BMI) and leisure-time physical activities, but not with occupational physical activity or total physical activity $^{(46)}$. This reinforces the importance of analysing in detail the different domains of habitual physical activity to better delineate their relationships with dietary and health outcomes.

Our findings have several limitations. First, the present study used a cross-sectional design. Thus, it was not possible to establish causal relationships. Second, our subjects were participants in a nutritional intervention study who generally had a higher education level and occupational status, along with a healthier lifestyle than the general population $^{(21,22)}$. Thus, caution may be needed when extrapolating these findings to the general population. In addition, although in the SU.VI.MAX study the number of participants lost to follow-up was relatively low ${ }^{(22)}$, a large number of participants were excluded from the present analyses because of missing dietary records or physical activity questionnaires. Data were also collected some years ago (1998) and behavioural patterns may have changed since then.

Third, the measurements of physical activity and TV viewing were derived from self-reporting, which might be a source of potential misclassification bias (especially over-reporting of duration and frequency for physical activity) $^{(47)}$. In addition, TV viewing represents only one aspect of sedentary behaviour and remains insufficient for determining all aspects of sedentary behaviour ${ }^{(13,48)}$, such as sitting down while travelling ${ }^{(49)}$ or time spent watching videos, playing video games and using a computer during leisure time. However, as noted by Sugiyama et $a l .{ }^{(50)}$, TV viewing time can be considered a robust marker of overall sedentary behaviour only in women.

In summary, the present results indicate that TV viewing, leisure-time and occupational physical activities are unrelated and are differentially associated with dietary patterns. The data emphasise the relationship between leisure-time physical activity and healthy food patterns, whereas TV viewing, a typical sedentary behaviour, appears to be related to unhealthy food habits. Therefore, identification of relationships between dietary patterns, physical activity and sedentary behaviour can enable us to better define healthy lifestyle patterns. The data from the present study on these relationships could provide information for targeting risk groups and defining health promotion and prevention programmes.

\section{Acknowledgements}

We thank the staff of the SU.VI.MAX study and also the volunteers who participated in this cohort. The present study was supported by the Institut National de la Santé et de la Recherche Médicale (Inserm), the Conservatoire National des Arts et Métiers (CNAM) and Paris 13 University. The present study is part of the Environmental LInks to physical Activity, Nutrition and hEalth (ELIANE) study. ELIANE is a project supported by the French National Research Agency (Agence Nationale de la Recherche, ANR-07-PNRA-004). The authors declare no conflict of interest. H. C. contributed to interpreting the results, drafted the manuscript and performed the final editing. E. K.-G. contributed to analysing dietary patterns and interpreting the results. S. B. performed the statistical analyses and contributed to designing the study, interpreting the results and writing the manuscript. C. S., B. C., C. W., M. T. and P. G. contributed to interpreting the results and editing the manuscript. $\mathrm{S}$. H. is coordinator of the SU.VI.MAX study and contributed to interpreting the results and editing the manuscript. J.-M. O. supervised the design, analysis and interpretation of data as well as writing of the manuscript. All authors critically reviewed the manuscript and approved the final version.

\section{References}

1. World Health Organization (2004) World Health Assembly 57.17: Global Strategy on Diet and Physical Activity. Geneva: WHO. 
2. US Department of Health and Human Services \& US Department of Agriculture (2005) Dietary Guidelines for Americans, 6th ed. Washington, DC: Government Printing Office.

3. US Department of Health and Human Services (1996) Physical Activity and Health: A Report of the Surgeon General. Atlanta, GA: Department of Health and Human Services, Centers for Disease Control and Prevention, National Center for Chronic Disease Prevention and Health Promotion.

4. Oppert JM, Thomas F, Charles MA, et al. (2006) Leisure-time and occupational physical activity in relation to cardiovascular risk factors and eating habits in French adults. Public Health Nutr 9, 746-754.

5. Camoes M \& Lopes C (2008) Dietary intake and different types of physical activity: full-day energy expenditure, occupational and leisure-time. Public Health Nutr 11, 841-848.

6. Hu FB (2002) Dietary pattern analysis: a new direction in nutritional epidemiology. Curr Opin Lipidol 13, 3-9.

7. Moeller SM, Reedy J, Millen AE, et al. (2007) Dietary patterns: challenges and opportunities in dietary patterns research an Experimental Biology Workshop, April 1, 2006. J Am Diet Assoc 107, 1233-1239.

8. Michels KB \& Schulze MB (2005) Can dietary patterns help us detect diet-disease associations? Nutr Res Rev 18, 241-248.

9. Newby PK \& Tucker KL (2004) Empirically derived eating patterns using factor or cluster analysis: a review. Nutr Rev 62, 177-203.

10. Kesse-Guyot E, Bertrais S, Peneau S, et al. (2009) Dietary patterns and their sociodemographic and behavioural correlates in French middle-aged adults from the SU.VI.MAX cohort. Eur J Clin Nutr 63, 521-528.

11. Pate RR, O'Neill JR \& Lobelo F (2008) The evolving definition of 'sedentary'. Exerc Sport Sci Rev 36, 173-178.

12. Hamilton MT, Hamilton DG \& Zderic TW (2007) Role of low energy expenditure and sitting in obesity, metabolic syndrome, type 2 diabetes, and cardiovascular disease. Diabetes 56, 2655-2667.

13. Biddle SJ (2007) Sedentary behavior. Am J Prev Med 33, 502-504.

14. Dunstan DW, Barr EL, Healy GN, et al. (2010) Television viewing time and mortality: The Australian Diabetes, Obesity and Lifestyle Study (AusDiab). Circulation 121, 384-391.

15. Platat C, Perrin AE, Oujaa M, et al. (2006) Diet and physical activity profiles in French preadolescents. Br J Nutr 96, 501-507.

16. Lioret S, Touvier M, Lafay L, et al. (2008) Dietary and physical activity patterns in French children are related to overweight and socioeconomic status. J Nutr 138, 101-107.

17. Lowry R, Wechsler H, Galuska DA, et al. (2002) Television viewing and its associations with overweight, sedentary lifestyle, and insufficient consumption of fruits and vegetables among US high school students: differences by race, ethnicity, and gender. $J$ Sch Health 72, 413-421.

18. Rosenberg DE, Norman GJ, Sallis JF, et al. (2007) Covariation of adolescent physical activity and dietary behaviors over 12 months. $J$ Adolesc Health 41, 472-478.

19. Jeffery RW \& French SA (1998) Epidemic obesity in the United States: are fast foods and television viewing contributing? Am J Public Health 88, 277-280.

20. Rehm CD, Matte TD, Van Wye G, et al. (2008) Demographic and behavioral factors associated with daily sugar-sweetened soda consumption in New York City adults. J Urban Health 85, 375-385.

21. Hercberg S, Preziosi P, Briancon S, et al. (1998) A primary prevention trial using nutritional doses of antioxidant vitamins and minerals in cardiovascular diseases and cancers in a general population: the SU.VI.MAX study - design, methods, and participant characteristics. SUpplementation en VItamines et Mineraux AntioXydants. Control Clin Trials 19, 336-351.

22. Hercberg S, Galan P, Preziosi P, et al. (2004) The SU.VI.MAX Study: a randomized, placebo-controlled trial of the health effects of antioxidant vitamins and minerals. Arch Intern Med 164, 2335-2342.

23. Le Moullec N, Deheeger M, Preziosi P, et al. (1996) Validation du manuel photos utilisé pour l'enquête alimentaire de l'étude SU.VI.MAX (Validation of the photo manual used for the collection of dietary data in the SU.VI.MAX study). Cabier de Nutrition et de Diététique 31, 158-164.

24. Hercberg S (coordinator) (2005) SU.VI.MAX Food Composition Table (in French). Paris, France: Les éditions INSERM/Economica.

25. Willett W \& Stampfer MJ (1986) Total energy intake: implications for epidemiologic analyses. Am J Epidemiol $\mathbf{1 2 4}$ $17-27$.

26. Vuillemin A, Oppert JM, Guillemin F, et al. (2000) Selfadministered questionnaire compared with interview to assess past-year physical activity. Med Sci Sports Exerc 32, 1119-1124.

27. Kriska AM, Knowler WC, LaPorte RE, et al. (1990) Development of questionnaire to examine relationship of physical activity and diabetes in Pima Indians. Diabetes Care 13, 401-411.

28. Pereira MA, FitzerGerald SJ, Gregg EW, et al. (1997) A collection of Physical Activity Questionnaires for health-related research. Med Sci Sports Exerc 29, S1-S205.

29. Ainsworth BE, Haskell WL, Whitt MC, et al. (2000) Compendium of physical activities: an update of activity codes and MET intensities. Med Sci Sports Exerc 32, S498-S504.

30. Duvigneaud N, Wijndaele K, Matton L, et al. (2007) Dietary factors associated with obesity indicators and level of sports participation in Flemish adults: a cross-sectional study. Nutr J 6, 26.

31. Schulze MB, Hoffmann K, Kroke A, et al. (2003) An approach to construct simplified measures of dietary patterns from exploratory factor analysis. Br J Nutr 89, 409-419.

32. Roman-Vinas B, Ribas Barba L, Ngo J, et al. (2009) Validity of dietary patterns to assess nutrient intake adequacy. Br J Nutr 101, Suppl. 2, S12-S20.

33. Eaton CB, McPhillips JB, Gans KM, et al. (1995) Crosssectional relationship between diet and physical activity in two southeastern New England communities. Am J Prev Med 11, 238-244.

34. Matthews CE, Hebert JR, Ockene IS, et al. (1997) Relationship between leisure-time physical activity and selected dietary variables in the Worcester Area Trial for Counseling in Hyperlipidemia. Med Sci Sports Exerc 29, 1199-1207.

35. Gillman MW, Pinto BM, Tennstedt S, et al. (2001) Relationships of physical activity with dietary behaviors among adults. Prev Med 32, 295-301.

36. Tormo MJ, Navarro C, Chirlaque MD, et al. (2003) Physical sports activity during leisure time and dietary intake of foods and nutrients in a large Spanish cohort. Int J Sport Nutr Exerc Metab 13, 47-64.

37. Fung TT, Hu FB, Yu J, et al. (2000) Leisure-time physical activity, television watching, and plasma biomarkers of obesity and cardiovascular disease risk. Am J Epidemiol 152, 1171-1178.

38. Fransson E, De Faire U, Ahlbom A, et al. (2004) The risk of acute myocardial infarction: interactions of types of physical activity. Epidemiology 15, 573-582.

39. Cleland VJ, Schmidt MD, Dwyer T, et al. (2008) Television viewing and abdominal obesity in young adults: is the 
association mediated by food and beverage consumption during viewing time or reduced leisure-time physical activity? Am J Clin Nutr 87, 1148-1155.

40. Scully M, Dixon H \& Wakefield M (2009) Association between commercial television exposure and fast-food consumption among adults. Public Health Nutr 12, 105-110.

41. Jackson DM, Djafarian K, Stewart J, et al. (2009) Increased television viewing is associated with elevated body fatness but not with lower total energy expenditure in children. Am J Clin Nutr 89, 1031-1036.

42. Pettee KK, Ham SA, Macera CA, et al. (2009) The reliability of a survey question on television viewing and associations with health risk factors in US adults. Obesity (Silver Spring) 17, 487-493.

43. Salmon J, Bauman A, Crawford D, et al. (2000) The association between television viewing and overweight among Australian adults participating in varying levels of leisure-time physical activity. Int J Obes Relat Metab Disord 24, 600-606.

44. Stamatakis E, Hirani V \& Rennie K (2009) Moderate-to-vigorous physical activity and sedentary behaviours in relation to body mass index-defined and waist circumference-defined obesity. Br J Nutr 101, 765-773.
45. Bertrais S, Preziosi P, Mennen L, et al. (2004) Sociodemographic and geographic correlates of meeting current recommendations for physical activity in middle-aged French adults: the Supplementation en Vitamines et Mineraux Antioxydants (SUVIMAX) Study. Am J Public Health 94, $1560-1566$.

46. Abu-Omar K \& Rutten A (2008) Relation of leisure time, occupational, domestic, and commuting physical activity to health indicators in Europe. Prev Med 47, 319-323.

47. Shephard RJ (2003) Limits to the measurement of habitual physical activity by questionnaires. Br J Sports Med 37, 197-206. discussion 206.

48. Clark BK, Sugiyama T, Healy GN, et al. (2009) Validity and reliability of measures of television viewing time and other non-occupational sedentary behaviour of adults: a review. Obes Rev 10, 7-16.

49. Frank LD, Andresen MA \& Schmid TL (2004) Obesity relationships with community design, physical activity, and time spent in cars. Am J Prev Med 27, 87-96.

50. Sugiyama T, Healy GN, Dunstan DW, et al. (2008) Is television viewing time a marker of a broader pattern of sedentary behavior? Ann Behav Med 35, 245-250. 